The following article is reprinted from the July 1968

issue of the Federal Reserve Bank of St. Louis Review.

\title{
Karl Brunner
}

\section{The Role of Money and Monetary Policy}

$\mathrm{T}$ HE DEVELOPMENT of monetary analysis in the past decade has intensified the debate concerning the role of money and monetary policy. Extensive research fostered critical examinations of the Federal Reserve's traditional descriptions of policy and of the arrangements governing policymaking. Some academic economists and others attribute the cyclical fluctuations of monetary growth and the persistent problem concerning the proper interpretation of monetary policy to the established procedures of monetary policy and the conceptions traditionally guiding policymakers.

The critique of established policy procedures, which evolved from this research into questions concerning the monetary mechanism, is derived from a body of monetary theory referred to in this paper as the Monetarist position. Three major conclusions have emerged from the hypotheses put forth. First, monetary impulses are a major factor accounting for variations in output, employment and prices. Second, movements in the money stock are the most reliable measure of the thrust of monetary impulses. Third, the behavior of the monetary authorities dominates movements in the money stock over business cycles.
A response to the criticisms of existing monetary policy methods was naturally to be expected and is welcomed. Four articles which defend present policy procedures have appeared during the past few years in various Federal Reserve publications. ${ }^{1}$ These articles comprise a countercritique which argues that monetary impulses are neither properly measured nor actually transmitted by the money stock. The authors reject the Monetarist thesis that monetary impulses are a chief factor determining variations in economic activity, and they contend that cyclical fluctuations of monetary growth cannot be attributed to the behavior of the Federal Reserve authorities. These fluctuation are claimed to result primarily from the behavior of commercial banks and the public.

The ideas and arguments put forth in these articles deserve close attention. The controversy defined by the critique of policy in professional studies and the countercritique appearing in Federal Reserve publications bears on issues of fundamental importance to public policy. Underlying all the fashionable words and phrases is the fundamental question: What is the role of monetary policy and what are the requirements of rational policymaking?
"Lyle Gramley and Samuel Chase, "Time Deposits in Monetary Analysis," Federal Reserve Bulletin, October 1965. John H. Kareken, "Commercial Banks and the Supply of Money: A Market Determined Demand Deposit Rate," Federal Reserve Bulletin, October 1967. J. A. Cacy,
"Alternative Approaches to the Analysis of the Financial Structure," Monthly Review, Federal Reserve Bank of Kansas City, March 1968. Richard G. Davis, "The Role of the Money Supply in Business Cycies," Monthly Review, Federal Reserve Bank of New York, April 1968. 
The following sections discuss the major aspects of the countercritique. These rejoinders may contribute to a better understanding of the issues, and the resulting clarification may remove some unnecessary disputes. Even though the central contentions of the controversy will remain, the continuous articulation of opposing points of view plays a vital role in the search for greater understanding of the monetary process.

\section{A SUMMAPI OF TWE

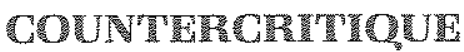

The four articles relied on two radically different groups of arguments. Gramley-Chase, Kareken and Cacy exploit the juxtaposition "New View versus Traditional View" as the central idea guiding their countercritique. The analytical framework developed by the critique is naturally stbsumed for this purpose under the "Traditional View" label. On the other hand, Davis uses the analytical framework developed by the critique in order to organize his arguments.

Gramley-Chase describe their general argument in the following words:

\begin{abstract}
"New) developments have reaffirmed the bankers' point of view that deposits are attracted, not created, as textbooks suggest. In this new environment, growth rates of deposits have become more suspect than ever as indicators of the conduct of monetary policy. . . A framework of analysis lis Fequired] from which the significance of time deposits and of changing time deposits can be deduced. Traditional methods of monetary analysis are not well suited to this task. The 'New View' in monetary economics provides a more useful analytical framework, In the new view, bankslike other financial institutions-are considered as suppliers of financial claims for the public to hold. and the public is given a significant role in determining the total amount of bank liabilities. . . . Traditional analysis. . fails to recognize that substitution between time deposits and securities may be an important source of pro-cyclical varia. tions in the stock of money even in the face of countercyolical central bank policy. ${ }^{* \prime z}$
\end{abstract}

This general argument guided the construction of an explicit model designed to emphasize the role of the public's and the banks' behavior in the determination of the money stock, bank credit and interest rates.

Kareken's paper supplements the GramleyChase arguments. He finds "the received money supply theory" quite inadequate. His paper is designed to improve monetary analysis by constructing a theory of an individual bank as a firm. This theory is offered as an explanation of a bank's desired balance sheet position. It also appears to form the basis of a model describing the interaction of the public's and the banks' behavior in the joint determination of the money stock, bank credit and interest rates. The whole development emphasizes somewhat suggestively the importance of the public's and banks' behavior in explanations of monetary growth. It is also designed to undermine the empirical hypotheses advanced by the Monetar. ist position. This is achieved by means of explicit references to specific and "obviously desirable" features of the model presented.

Cacy's article develops neither an explicit framework nor a direct critique of the basic propositions advanced by the Monetarist thesis. However, he provides a useful summary of the general position of the countercritique. The Monetarist analysis is conveniently subsumed by Cacy under a "Traditional View" which is jux. taposed to a "New View" of monetary mechanisms: "The new approach argues. . that there is no essential difference between the manner in which the liabilities of banks and nonbank financial institutions are determined. Both types of institutions are subject in the same way to the portfolio decisions of the public." ${ }^{\prime \prime}$ The new approach is contrasted with the Traditional View, which "obscures the important role played by the public and overstates the role played by the central bank in the determination of the volume of money balances. ${ }^{\prime \prime 4}$ The general comparison developed by Cacy suggests quite clearly to the reader that the Traditional View allegedly espoused by the Monetarist position cannot match the "realistic sense" of the New View advocated by the countercritique.

In the context of the framework developed by the critique, Davis questions some basic propositions of the Monetarist position: 
"In the past five to ten years, however, there has come into increasing prominence a group of economists who would like to go considerably beyond the simple assertion that the behavior of money is a significant factor influencing the behavior of the economy. ... In order to bring a few of the issues into sharper focus, this article will take a look at some evidence for the 'money supply' view....

It confines itself to examining the historical relationship between monetary cycles and cycles in general business. The article concludes that the relationship between these two kinds of cycles does not, in fact, provide any real support for the view that the behavior of money is the predominant determinant of fluctuations in business activity. Moreover, the historical relationship between cycles in money and in business cannot be used to demonstrate that monetary policy is, in its effects, so long delayed and so uncertain as to be an unsatisfactory countercyclical weapon."s

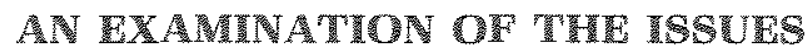

A careful survey of the countercritique yielded the following results. The Gramley-Chase, Kareken, and Cacy papers parade the New View in order to question the status of empirical theories used by the Monetarist critique in its examination of monetary policy. The Davis paper questions quite directly, on the other hand, the existence and relevance of the evidence in support of the Monetarist position, and constitutes a direct assault on the Monetarist critique. The others constitute an indirect assault which attempts to devalue the critique's analysis, and thus to destroy its central propositions concerning the role of money and monetary policy.

The indirect assault on the Monetarist position by Gramley.Chase, Kareken and Cacy requires a clarification concerning the nature of the New View. A program of analysis must be clearly distinguished from a research strategy and an array of specific conjectures. ${ }^{6}$ All three aspects are usually mixed together in a general description. It is important to understand, however, that neither research strategy nor specific em-

5Davis, pp. 63-64.

GThese three aspects of the New View will subsequently be elaborated more fully. Their program of analysis refers to the application of relative price theory to analysis of financial markets and financial institutions. Their research strategy refers to a decision to initiate analysis in the context of a most general tramework. Their specific conjectures refer to propositions concerning the causes of fluc- pirical conjectures are logical implications of the general program. The explicit separation of the three aspects is crucial for a proper assessment of the New View.

Section A examines some general characteristics of the countercritique's reliance on the New View. It shows the New View to consist of a program acceptable to all economists, a research strategy rejected by the Monetarist position, and an array of specific conjectures advanced without analytical or empirical substantiation. Also, not a single paper of the counter. critique developed a relevant assessment of the Monetarist's empirical theories or central propositions.

In sections $B$ and $C$ detailed examinations of specific conjectures centered on rival explanations of cyclical fluctuations of monetary growth are presented. The direct assault on the Monetarist position by Davis is discussed in some detail in section $D$. This section also states the crucial propositions of the Monetarist thesis in order to clarify some aspects of this position. This reformulation reveals that the reservations assembled by Davis are quite innocuous. They provide no analytical or empirical case against the Monetarist thesis. Conjectures associated with the interpretation of monetary policy (the "indicator problem") are presented in section $\mathrm{E}$.

\section{A. The New Vien}

The countercritique has apparently been decisively influenced by programmatic elabora tions originally published by Gurley-Shaw and James Tobin. ${ }^{7}$ The program is most faithfully reproduced by Cacy, and it also shaped the arguments guiding the model construction by Kareken and Gramley-Chase. The New View, as a program, is a sensible response to a highly unsatisfactory state of monetary analysis inherited in the late 1950's. A money and banking syndrome perpetuated by textbooks obstructed the application of economic analysis to the financial sector. At most, this inherited litera. ture contained only suggestive pieces of analysis. It lacked a meaningful theory capable of fuation of monetary growth and propositions about proper interpretation of policy.

7John G. Gurley and Edward F. Shaw, Money in a Theory of Finance, (Washington: Brookings institute, 1960). James Tobin, "Commercial Banks as Creators of Money," Banking and Monetary Studies, ed. Deane Carson (R. D. Irwin, 1963). 
explaining the responses of the monetary sys. tem to policy actions or to influences emanating from the real sector. The New View proposed a systematic application of economic analysis, in particular an application of relative price theory, to the array of financial intermediaries, their assets and liabilities.

This program is most admirable and incontestable, but it cannot explain the conflict revealed by critique and countercritique. The Monetarist approach accepted the general principle of applying relative price theory to the analysis of monetary processes. In addition, this approach used the suggestions and analytical pieces inherited from past efforts in order to develop some specific hypotheses which do explain portions of our observable environment. The New Viewers' obvious failure to recognize the limited content of their programmatic statements only contributes to maintenance of the conflict.

A subtle difference appears, however, in the research strategy. The New View was introduced essentially as a generalized approach, including a quite formal exposition, but with little attempt at specific structuring and empirical content. The most impressive statements propagated by the New View were crucially influenced by the sheer formalism of its exposition. In the context of the New View's almost empty form, little remains to differentiate one object from another. For instance, in case one only admits the occurrence of marginal costs and marginal yields associated with the actions of every household, firm, and financial intermediary, one will necessarily conclude that banks and non-bank financial intermediaries are restricted in size by the same economic forces and circumstances. In such a context there is truly no essential difference between the deter. mination of bank and non-bank intermediary liabilities, or between banks and non-bank in- termediaries, or between money and other financial assets.

The strong impressions conveyed by the New View thus result from the relative emptiness of the formulation which has been used to elaborate their position. In the context of the formal world of the New View, "almost everything is almost like everything else." This undifferentiated state of affairs is not, however, a property of our observable world. It is only a property of the highly formal discussion designed by the New View to overcome the unsatisfactory state of monetary analysis still prevailing in the late 1950 's or early 1960's.

Two sources of the conflict have been recognized thus far. The Monetarists' research strategy was concerned quite directly with the construction of empirical theories about the monetary system, whereas the New View indulged, for a lengthy interval, in very general programmatic excursions. Moreover, the New Viewers apparently misconstrued their program as being a meaningful theory about our observable environment. This logical error contributed to a third source of the persistent conflict.

The latter source arises from the criticism addressed by the New Viewers to the Monetarists' theories of money supply processes. Three of the papers exploit the logically dubious but psychologically effective juxtaposition between a "New View" and a "Traditional View." In doing this they fail to distinguish between the inherited state of monetary system analysis typically reflected by the money and banking textbook syndrome and the research output of economists advocating the Monetarist thesis. This distinction is quite fundamental. Some formal analogies misled the New Viewers and they did not recognize the logical difference between detailed formulations of empirical theories on

\footnotetext{
sAdequate analysis of the medium of exchange function of money, or of the conditions under which inside money becomes a component of wealth, was obstructed by the programmatic state of the New View. The useful analysis of the medium-of-exchange function depends on a decisive rejection of the assertion that "everything is almost like everything else." This analysis requires proper recognition that the marginal cost of information concerning qualities and properties of assets differs substantially between assets, and that the marginal cost of readjusting asset positions depends on the assets involved. The analysis of the wealth position of inside money requires recognition of the marginal productivity of inside money to the holder. Adequate attention to the relevant differences between
}

various cost or yield functions associated with different assets or positions is required by both problems. The blandness of the New View's standard program cannot cope with these issues. The reader may consult a preliminary approach to the analysis of the medium of exchange function in the paper by Karl Brunner and Allan $H$. Meltzer, in the Journal of Finance, 1964, listed in footnote 9. He should also consult for both issues the important book by Boris Pesek and Thomas Saving. Money, Wealth and Economic Theory, The Macmillan Company, New York, 1967, of the paper by Harry Johnson, "Inside Money, Outside Money, Income, Wealth and Welfare in Manetary Theory,"' to be published in the Journal of Money, Credit and Banking, December 1968. 
the one side and haphazard pieces of unfinished analysis on the other side. ${ }^{9}$

A related failure accompanies this logical error. There is not the slightest attempt to assess alternative hypotheses or theories by systematic exposure to observations from the real world. It follows, therefore, that the countercritique scarcely analyzed the empirical theories advanced by the Monetarist critique and consequently failed to understand the major implications of these theories.

For instance, they failed to recognize the role assigned by the Monetarist view to banks' behavior and the public's preferences in the monetary process. The objection raised by the New View that "the formula lexpressing a basic framework used to formulate the hypothesis] obscures the important role played by the public" has neither analytical basis nor meaning. In fact, the place of the public's behavior was discussed in the Monetarist hypotheses in some detail. Moreover, the same analysis discussed the conditions under which the public's behavior dominates movements of the money stock and bank credit. ${ }^{10}$ It also yielded informa-

${ }^{9}$ As examples of the empirical work performed by the Monetarists, the reader should consult the following works: Milton Friedman and Anna Jacobson-Schwartz. A Monetary Mistory of the United States, 1867-1960, (Princeton: Princeton University Press, 1963). Philip Cagan, Determinants and Effects of Changes in the Stock of Money, (Columbia: Columbia University Press, 1965). Karl Brunner and Allan $H$. Melzzer, "Some Further investigations of Demand and Supply Functions for Money," Journal of Finance, Volume XIX, May 1964. Karl Brunner and Allan $H$. Meitzer, "A Credit-Market Theory of the Money Supply and an Explanation of Two Puzzles in U.S. Monetary Policy," Essays in Honor of Marco Fanno, 1966, Padova, Italy. Karl Brunner and Robert Crouch, "Money Supply Theory and British Monetary Experience," Methods of Operations Research II-Essays in Honor of Withelm Krelle, ed. Rudolf Henn (Published in Meisenheim, Germany, by Anton Hain, 1966). Karl Brunner, "A Schema for the Supply Theory of Money," International Economic Review, 1961. Kanl Brunner and Allan H. Meltzer, "An Alternative Approach to the Monetary Mechanism," Subcommittee on Domestic Finance, Committee on Banking and Currency, House of Representatives, August 17, 1964.

10The reader witl find this analysis in the following papers: Karl Brunner and Allan H. Meltzer, "Liquidity Traps for Money, Bank Credit, and Interest Rates," Journal of Political Economy, April 1968. Karl Brunner and Allan $\mathrm{H}$. Meltzer, "A Credit-Market Theory of the Money Supply and an Explanation of Two Puzzles in U.S. Monetary Policy," Essays in Honor of Marco Fanno. Padova, Italy, 1966.

11The reader is, of course, aware that these assertions require analytic substantiation. Such substantiation cannot be supplied within the confines of this article. But the reader could check for himself. If he finds, in the context of the countercritique, an analysis of the monetarists' mafor hypotheses, an examination of implication, and ex- tion about the response of bank credit, money stock and time deposits to changes in ceiling rates, or to changes in the speed with which banks adjust their deposit-supply conditions to evolving market situations. Every single aspect of the banks' or the public's behavion emphasized by the countercritique has been analyzed by the Monetarist's hypotheses in terms which render the results empirically assessable. Little remains, consequently, of the suggestive countercritique assembled in the papers by Gramley-Chase, Kareken and Cacy. ${ }^{11}$

\section{B. A Monetanist Examination of the New View's Money Supply Theory}

Three sources of the conflict have been discussed thus far. Two sources were revealed as logical misconstruals, involving inadequate construction and assessment of empirical theories. A third source pertains to legitimate differences in research strategy. These three sources do not explain all major aspects of the conflict. Beyond the differences in research strategy and logical misconceptions, genuinely substantive issues remain. Some comments of protagonists advocating

posure to observations, I would have to withdraw my statements. A detailed analysis of the banks' and the pubic's role in the money supply, based on two different hypotheses previously reported in our papers will be developed in our forthcoming books. This analysis, by its very existence, falsifies some major objections made by Cacy or Gramley-Chase. Much of their criticism is either innocuous or fatuous. Gramley Chase indulge, for in stance, in modality statements, i,e. statements obtained from other statements by prefixing a modality qualifier like "maybe" or "possibly." The result of qualifying an em. pirical statement always yields a staiement which is necessarily true but also quite uninformative. The modality game thus yields logicaly pointless but psychologically effective sentences. Cacy manages, on the other hand, some astonishing assertions. The New View is credted with the discovery inat excess reserves vary over time. He totally disregards the major contributions to the analysis of excess reserves emanating from the Monetarisis' research. A detaited analysis of excess reserves was developed by Milton Friedman and Anna Schwarz in the book mentioned in footnote 9 . The reader shouid also note the work by George Morrison, Liquidity Preferences of Commercial Banks, (Chicago: Unversity of Chicago Press, 1966), and the study by Peter Frost, 'Banks' Demand for Excess Reserves," an unpublished dissertation submitted to the University of California at Los Angeles, 1966. The classic example of an innocuous achievement was supplied by Cacy with the assertion: ". . . the actual volume of money balances determined by competizive market forces may or may not be equat to the upper limit established by the central bank" (p. 8). Indeed, we knew this before the New View or Any View, just as we always knew that "it may or may not rain komorrow." The reader should note that similar statements were produced by other authors with all the appearances of meaningful elaborations. 
the New View should probably be interpreted as conjectures about hypotheses to be expected from their research strategy. It should be clearly understood that such conjectures are not logical implications of the guiding framework. Instead, they are pragmatic responses to the general emphasis associated with this approach.

A first conjecture suggests that the money stock and bank credit are dominated by the public's and the Banks' behavior. It is suggested, therefore, that cyclical fluctuations of monetary growth result primarily from the responses of banks and the public to changing business con" ditions. A second conjecture naturally supplements the above assertions. It is contended that the money stock is a thoroughly "untrustworthy guide to monetary policy."

Articles by Gramley-Chase and Kareken attempt to support these conjectures with the aid of more explicit analytical formulations allegedly expressing the general program of the New View. The paper contributed by Gramley-Chase has been critically examined in detail on another occasion, and only some crucial aspects relevant for our present purposes will be considered at this point. ${ }^{12}$ Various aspects of the first conjecture are examined in this and the next section. The second conjecture is examined in sections $\mathrm{D}$ and $\mathrm{E}$.

A detailed analysis of the Gramley-Chase model demonstrates that it implies the following reduced form equations:

$$
\begin{array}{ll}
\mathrm{M}=\mathrm{g}\left(\mathrm{B}^{\mathrm{e}}, \mathrm{Y}, \mathrm{c}\right) & \mathrm{g}_{1}>0<\mathrm{g}_{2^{\prime}} \\
\mathrm{E}=\mathrm{h}\left(\mathrm{B}^{\mathrm{e}}, \mathrm{Y}, \mathrm{c}\right) & \mathrm{h}_{\mathrm{1}}>0>\mathrm{h}_{\mathrm{z}^{\prime}} \text { and } \mathrm{h}_{1}>\mathrm{g}_{1}{ }^{13}
\end{array}
$$

explaining the money stock $(\mathrm{M})$ and bank credit (E) in terms of the extended monetary base $\left(B^{c}\right)$, the level of economic activity expressed by national income at current prices (Y), and the ceiling rate on time deposits (c). ${ }^{14}$

The Gramley Chase model implies that monetary policy does affect the money stock and bank credit. It also implies that the money stock responds positively and bank credit negatively to economic activity. The model thus differs from the Monetarist hypotheses which imply that both bank credit and the money stock respond positively to economic activity. The GramleyChase model also implies that the responses of both the money stock and bank credit to monetary actions are independent of the general scale of the public's and the banks' interest elasticities. Uniformly large or small interest elasticities yield the same response in the money stock or bank credit to a change in the monetary base.

A detailed discussion of the implications derivable from a meaningfully supplemented Gramley-Chase model is not necessary at this point. We are foremost interested in the relation between this model and the propositions mentioned in the previous paragraph. The first proposition can be interpreted in two different ways. According to one interpretation, it could mean that the marginal multipliers $g_{i}$ and $h_{i}$ $(i=1,2)$ are functions of the banks' and the public's response patterns expressing various types of substitution relationships between different assets. This interpretation is, however, quite innocuous and yields no differentiation relative to the questioned hypotheses of the Monetarist position.

A second interpretation suggests that the growth rate of the money stock is dominated by the second component (changes in income) of the differential expression:

$$
\Delta \mathrm{M}=\mathrm{g}_{1} \Delta \mathrm{B}^{\mathrm{e}}+\mathrm{g}_{2} \Delta \mathrm{Y}
$$

This result is not actually implied by the Gramley-Chase model, but it is certainly consistent with the model. However, in order to derive the desired result, their model must be supplemented with special assumptions about the relative magnitude of $g_{1}$ and $g_{2^{\prime}}$ and also about the comparative cyclical variability of $\Delta \mathrm{B}^{*}$ and $\Delta Y$. This information has not been provided by the authors.

Most interesting is another aspect of the model which was not clarified by the authors. Their model implies that policymakers could easily avoid procyclical movements in $\Delta M$. This model exemplifying the New View thus yields
12The reader may consult my chapter "Federal Reserve Policy and Monetary Analysis' in Indicators and Targets of Monetary Policy, ed., by Kart Brunner, to be published by Chandler House Publishing Co., San Francisco. This book also contains the original article by Gramley-Chase. Further contributions by Patric $\mathrm{H}$. Hendershott and Robert Weintraub survey critically the issues raised by the Gramley-Chase paper. 13n the Gramley-Chase model, $g_{3}$ and $h_{3}$ are indeterminant.

14This implication was demonstrated in my paper listed in tootnote 12. The monetary base is adjusted for the accumulated sum of reserves liberated from or impounded in required reserves by changes in requirement ratios. 
little justification for the conjectures of its proponents.

A central property of the Gramley-Chase model must be considered in the light of the programmatic statements characterizing the New View. Gramley Chase do not differentiate between the public's asset supply to banks and the public's demand for money. This procedure violates the basic program of the New View, namely, to apply economic analysis to an array of financial assets and financial institutions. Economic analysis implies that the public's asset supply and money demand are distinct, and not identical behavior patterns. This difference in behavior patterns is clearly revealed by different responses of desired money balances and desired asset supply to specific stimuli in the environment. For instance, an increase in the expected real yield on real capital raises the public's asset supply but lowers the public's money demand. It follows thus that a central analytical feature of the Gramley-Chase model violates the basic and quite relevant program of the New View.

Karenken's construction shares this fundamental analytical flaw with the Gramley-Chase model, but this is not the only problem faced by his analysis. The Karenken analysis proceeds on two levels. First, he derives a representative bank's desired balance sheet position. For this purpose he postulates wealth maximization subject to the bank's balance sheet relation between assets and liabilities, and subject to reserve requirements on deposits. On closer examination, this analysis is only applicable to a monopoly bank with no conversion of deposits into currency or reserve flows to other banks. In order to render the analysis relevant for a representative bank in the world of reality, additional constraints would have to be introduced which modify the results quite substantially. It is also noteworthy that the structural properties assigned by Karenken to the system of market relations are logically inconsistent with the implications one can derive from the author's analysis of firm behavior developed on the first level of his investigation.

This disregard for the construction of an economic theory relevant for the real world is carried into the second level of analysis where the author formulates a system of relations describing the joint determination of interest rates, bank credit, and money stock. A remarkable feature of the Karenken model is that it yields no implications whatsoever about the response of the monetary system to actions of the Federal Reserve. It can say nothing, as it stands, about either open market operations or about discount rate and reserve requirement actions. This model literally implies, for instance, that the money stock and the banking system's deposit liabilities do not change as a result of any change in reserve requirements ratios.

None of the conjectures advanced by the countercritique conceming the behavior of the money stock and the role of monetary policy find analytical support in Karenken's analysis. To the extent that anything is implied, it would imply that monetary policy operating directly on bank reserves or a mysterious rate of return on reserves dominates the volume of deposits-a practically subversive position for a follower of the New View. ${ }^{1.5}$

\section{Altemanive Explanations of Cyclical Fuctuations in Monetary Growerh}

The examination thus far in this article has shown that even the most explicit formulation (Gramley-Chase) of the countercritique, allegedly representing the New View with respect to monetary system analysis, does assign a significant role to monetary policy. This examination also argued that the general emphasis given by the New View to the public's and the banks' behavior in determination of the money stock and bank credit does not differentiate its product from analytical developments arising from the Monetarist approach. It was also shown that

\footnotetext{
${ }^{15}$ Two direct objections made to the Brunner-Meltzer analysis by Kareken should be noted. He finds that the questioned hypotheses do not contain "a genuine supply function" of deposits. Accepting Karenken's terminology, this is true, but neither does the Gramley-Chase model contain such a supply function. But the objection has no evidential value anyway. If a hypothesis were judged unsatisfactory because some aspects are omitted, al hypotheses are "unsatisfactory." Moreover, the cognitive status of a empirical hypothesis does not improve simply
}

because an "analytical underpinning" has been provided. Karenken also finds fault with our use of the term "money supply function." Whether or not one agrees with this terminological preferences surely does not affect the relation between observations and statements supplied by the hypothesis. And it should be clear that the status of hypothesis depends only on this relation, and not on names attached to statements. 
the only explicit formulation advanced by the New Viewers does not provide a sufficient basis for their central conjectures. It is impossible to derive the proposition from the Gramley-Chase model that the behavior of the public and banks, rather than Federal Reserve actions, dominated movements in the money supply. But the declaration of innocence by the countercriti. que on behalf of the monetary authorities with respect to cyclical fluctuations of monetary growth still requires further assessment.

The detailed arguments advanced to explain the observed cyclical fluctuations of monetary growth differ substantially among the contributors to the countercritique. Gramley-Chase maintain that changing business conditions modify relative interest rates, and thus induce countercyclical movements in the time deposit ratio. These movements in demand and time deposits generate cyclical fluctuations in monetary growth. On the other hand, Cacy develops an argument used many years ago by Wicksell and Keynes, but attributes it to the New View. He recognizes a pronounced sensitivity of the money stock to variations in the public's money demand or asset supply. These variations induce changes in credit market conditions. Banks, in turn, respond with suitable adjustments in the reserve and borrowing ratios. The money stock and bank credit consequently change in response to this mechanism.

Davis actually advances two radically different conjectures about causes of cyclical fluctuations of monetary growth. The first conjecture attributes fluctuations of monetary growth to the public's and banks' responses. Changing business conditions modify the currency ratio, the banks' borrowing ratio, and the reserve ratio. The resulting changes generate the observed movements in money. His other conjecture attributes fluctuations in monetary growth to Federal Reserve actions: "the state of business influences decisions by the monetary authorities to supply reserves and to take other actions likely to affect the money supply." ${ }^{\prime \prime}$
The various conjectures advanced by GramleyChase, Cacy, and Davis in regard to causes of movements in money and bank credit can be classified into two groups. One set of conjectures traces the mechanism generating cyclical fluctuations of monetary growth to the responses of banks and the public; the behavior of monetary authorities is assigned a comparatively minor role. The other group of conjectures recognizes the predominant role of the behavior of monetary authorities.

In the following analysis the framework provided by the Monetarist view will be used to assess these conflicting conjectures. The emphasis concerning the nature of the causal mechanisms may differ between the various conjectures regarding sources of variations in money, but the following examination will be applied to an aspect common to all conjectures emphasizing the role of public and bank behavior.

In the context of the Monetarist framework, the money stock ( $M$ ) is exhibited as a product of a multiplier ( $\mathrm{m}$ ) and the monetary base (B), (such that $\mathrm{M}=\mathrm{mB}$ ). This framework, without the supplementary set of hypotheses and theories bearing on the proximate determinants of money summarized by the multiplier and the base, is completely neutral with respect to the rival conjectures; it is compatible with any set of observations. This neutrality assures us that its use does not prejudge the issue under consideration. The Monetarist framework operates in the manner of a language system, able to express the implications of the competing conjectures in a uniform manner.

The first group of conjectures advanced by the countercritique (behavior of the public and banks dominates movements in moneyl implies that variations in monetary growth between upswings and downswings in business activity are dominated by the variations in the monetary multiplier. The second group (behavior of monetary authorities dominates movements in

\footnotetext{
16 Davis, p. 66 . One argument about monetary policy in the same paper requires clarification. Davis asserts on p. 68 that the money supply need not be the objective of policy, and "given this tact, the behavior of the rate of growth of the money supply during the period cannot be assumed to be simply and directly the result of monetary policy decisions alone." This quote asserts that the money supply is "simply and directly the result of policy atone" whenever policy uses the money supply as a target. This is in a
}

sense correct. But the quote could easily be misinterpreted due to the ambiguity of the term "policy." This term is frequently used to designate a strategy guiding the adjustment of policy variables. Is is also frequently used to fefer to the behavior of the policy variables or directly to the variables as such. The quote is quite acceptable in the first sense of "policy," but thoroughty unacceptable in the second sense. 
money) implies that, in periods with unchanged reserve requirement ratios and ceiling rates on time deposits, variations in the monetary base dominate cyclical changes in monetary growth. The movements of the monetary multiplier which are strictly attributable to the changing of requirement ratios can be separated from the total contribution of the multiplier and combined with the monetary base. With this adjustment, the second group of conjectures implies that the monetary base, supplemented by the contribution of reserve requirement changes to the multiplier, dominates variations in the money stock.

In this examination of contrasting explanations of monetary fluctuations, values of the money stock (M), the multiplier (m), and the monetary base adjusted for member bank borrowing (B) are measured at the initial and terminal month of each half business cycle (i.e., expansions and contractions) located by the National Bureau of Economic Research. We form the ratios of these values and write:

$$
\frac{M_{1}}{M_{0}}=\frac{m_{1}}{m_{0}} \frac{B_{1}}{B_{0}} ; \text { or } \mu=\alpha \beta
$$

The subscript 1 refers to values of the terminal month and the subscript 0 to values of the initial month. These ratios were measured for each half cycle in the period March 1919 to December 1966. They were computed for two definitions of the money stock, inclusive and exclusive of time deposits, with corresponding monetary multipliers.

Kendall's rank correlation coefficients between the money stock ratios $(\mu)$ and the multiplier ratios $(\alpha)$, and between $(\mu)$ and the monetary base ratio $(\beta)$ were computed. We denote these correlation coefficients with $\varrho(\mu, \alpha)$ and $\varrho(\mu, \beta)$. The implications of the two rival conjectures can now be restated in terms of the two coefficients. The first group of conjectures implies that $\varrho(\mu, \alpha)>\varrho(\mu, \beta)$; while the second group implies that in periods of unchanged reserve requirements ratios and ceiling rates on time deposits, the coefficient $\varrho(\mu, \beta)$ exceeds the coefficient $\varrho(\mu, \alpha)$. The second group implies nothing about the relation of the two coefficients in periods of changing reserve requirements and ceiling rates on time deposits. It follows, therefore, that observations yielding the inequality $\varrho(\mu, \beta>\varrho(\mu, \alpha)$ disconfirm the first group and confirm the second group.

The correlations obtained are quite unambiguous. The value of $e(\mu, \beta)$ is .537 for the

\section{Table 1}

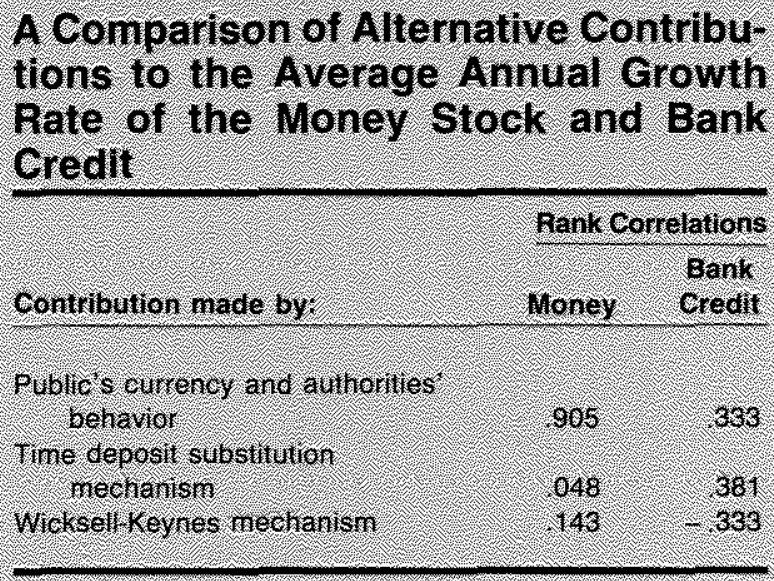

Remarks The f gures hsted state the rank correlation between the average growh tale of the noney stoek and bark credt Win wee diterent contubuting sources

whole sample period, whereas $\varrho(\mu, \alpha)$ is only .084. The half-cycle from 1929 to 1933 was omitted in the computations, because movements in the money stock and the multiplier were dominated by forces which do not discriminate between the rival conjectures under consideration. The sample period, including 1929 to 1933 , still yields a substantially larger value for $\varrho(\mu, \beta)$. The same pattern also holds for subperiods. In particular, computations based on observations for 1949 to 1966 confirm the pattern observed for the whole sample period. The results thus support the second group of conjectures but not the first group. These results also suggest, however, that forces operating through the multiplier are not quite negligible. The surprisingly small correlation $\varrho(\mu$, $\alpha$ ) does not adequately reveal the operation of these forces. Their effective operation is revealed by the correlation $\varrho(\mu, \beta)$, which is far from perfect, even in subperiods with constant reserve requirement ratios. This circumstance suggests that the behavior of the public and banks contributes to the cyclical movements of monetary growth. The main result at this stage, however, the clear discrimination between the two groups of conjectures. The results are quite unambiguous on this score.

Additional information is supplied by table I. For each postwar cycle beginning with the downswing of 1948-49, the average annual growth rate of the money stock was computed. The expression $\mathrm{M}=\mathrm{mb}$ was then used to compute the contribution to the average growth 


\section{Table II}

\section{Regressions of the Money Supply On the Monetary Base and Gross National Product*}

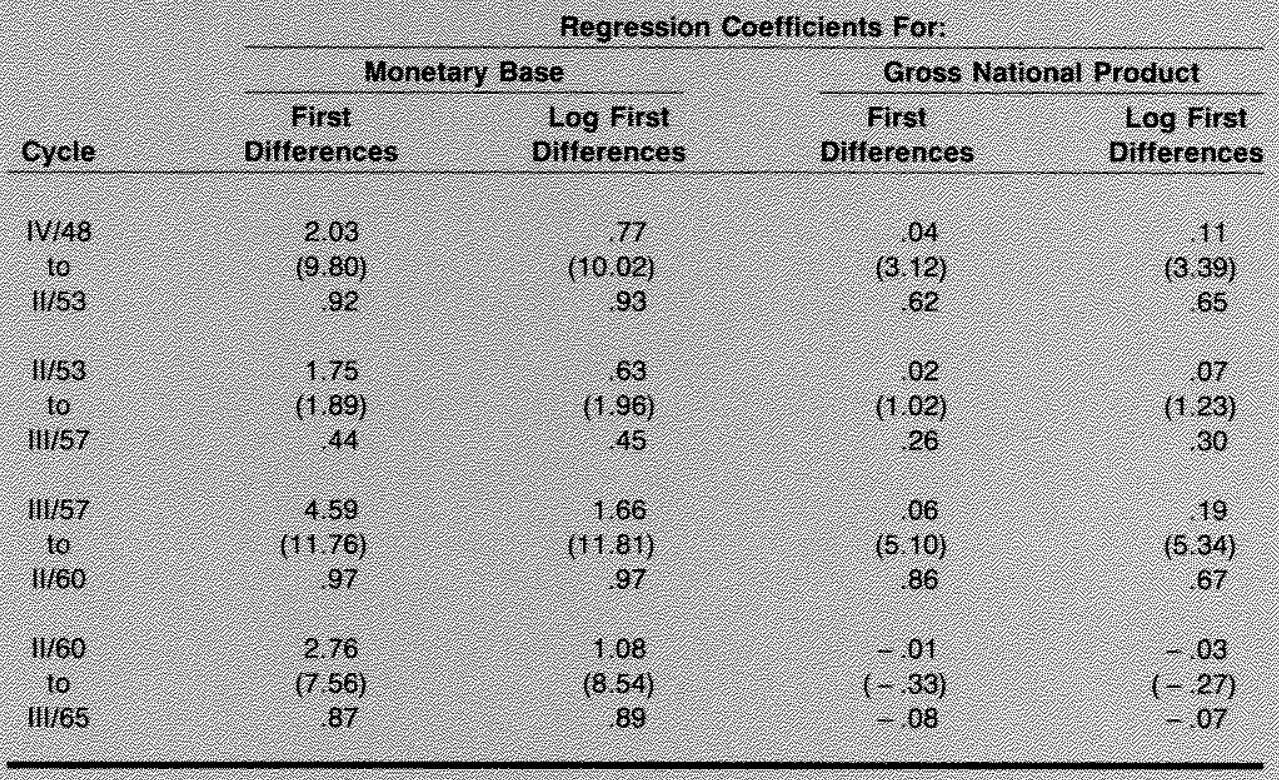

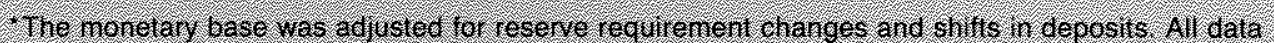

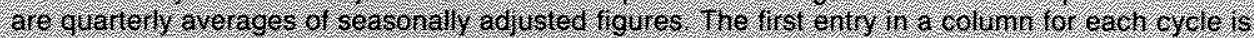

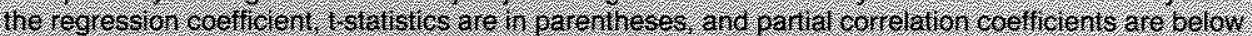
the testatistics:

rate of money from three distinct sources: (i) the behavior of monetary authorities (i.e., the monetary base and reserve requirement ratios), and the public's currency behavior, (ii) the time deposits substitution process, and, (iii) the variations in the excess reserve and borrowing ratios of commercial banks (Wicksell-Keynes mechanism).

The rank correlations between each contribution, and the average growth rate of the money stock over all postwar half-cycles clearly sup port the conclusion of the previous analysis that cyclical movements in the money stock are dominated by Federal Reserve actions.

Table I also presents the results of a similar examination bearing on causes of movements in bank credit. The reader should note the radical difference in the observed patterns of correlation coefficients. The behavior of monetary authorities, supplemented by the public's currency behavior, does not appear to dominate the behavior of bank credit. The three sources contributing to the growth rate of money all exerted influences of similar order on bank credit.
It appears that bank credit is comparatively less exposed to the push of Federal Reserve actions than was the money stock. On the other hand, the money stock is less sensitive than bank credit to the time-deposit substitution mechanism emphasized by Gramley-Chase, and the Wicksell-Keynes mechanism suggested by Cacy. Most astonishing, however, is the negative association between the average growth rate of bank credit and the Wicksell-Keynes mechanism emphasized by Cacy.

It should also be noted that the average growth rate of money conforms very clearly to the business cycle. Such conformity does not hold for bank credit over the postwar halfcycles. This blurring occurred particularly in periods when the ceiling rate on time deposits was increased. These periods exhibit relatively large contributions to the growth rate of bank credit emanating from the time deposit substitution mechanism.

A regression analysis (table II) of the reduced form equations derived from the Gramley-Chase model confirms the central role of the monetary 
base in the money supply process. Estimates of the regression coefficient relating money to income are highly unstable among different sample periods, relative to the coefficient relating money to the monetary base. Furthermore, estimates of regression coefficients relating money to income occur in some periods with signs which contradict the proposition of Gramley-Chase and Cacy, or exhibit a very small statistical significance. These diverse patterns of coefficients do not occur for the estimates of coefficients relating money and the monetary base. It is also noteworthy that the average growth rate of the monetary base (adjusted for changes in reserve requirement ratios), over the upswings, exceeds without exception the average growth rate of adjacent downswings. This observation is not compatible with the contention made by Gramley-Chase that policy is countercyclical.

Additional information is supplied by table III, which presents some results of a spectral analysis bearing on the monetary base and its sources. Spectral analysis is a statistical procedure for decomposing a time series into seasonal, cyclical, and trend movements. After such an analysis was conducted on the monetary base and its sources, a form of correlation analysis was run between movements in the monetary base and movements in its various sources. The results of this procedure (table III) indicate that movements in Federal Reserve credit dominate seasonal and cyclical movements in the monetary base.

In summary, preliminary investigations yield no support for the contention that the behavior of banks and the public dominates cyclical movements in the money stock. The conjectures advanced by Gramley-Chase or Cacy are thus disconfirmed, whereas Davis' second conjecture that fluctuations in monetary growth may be attributed to Federal Reserve actions seems substantially more appropriate. However, further investigations are certainly useful.

\section{PeVvance of Money and Wonetrin Achons with Wespect 10 Heonomic Activin}

At present, a broad consensus accepts the relevance of money and monetary policy with respect to economic activity. But this consensus concerning the relevance of money emerges from two substantially different views about the nature of the transmission mechanism. One

\section{Table 11}

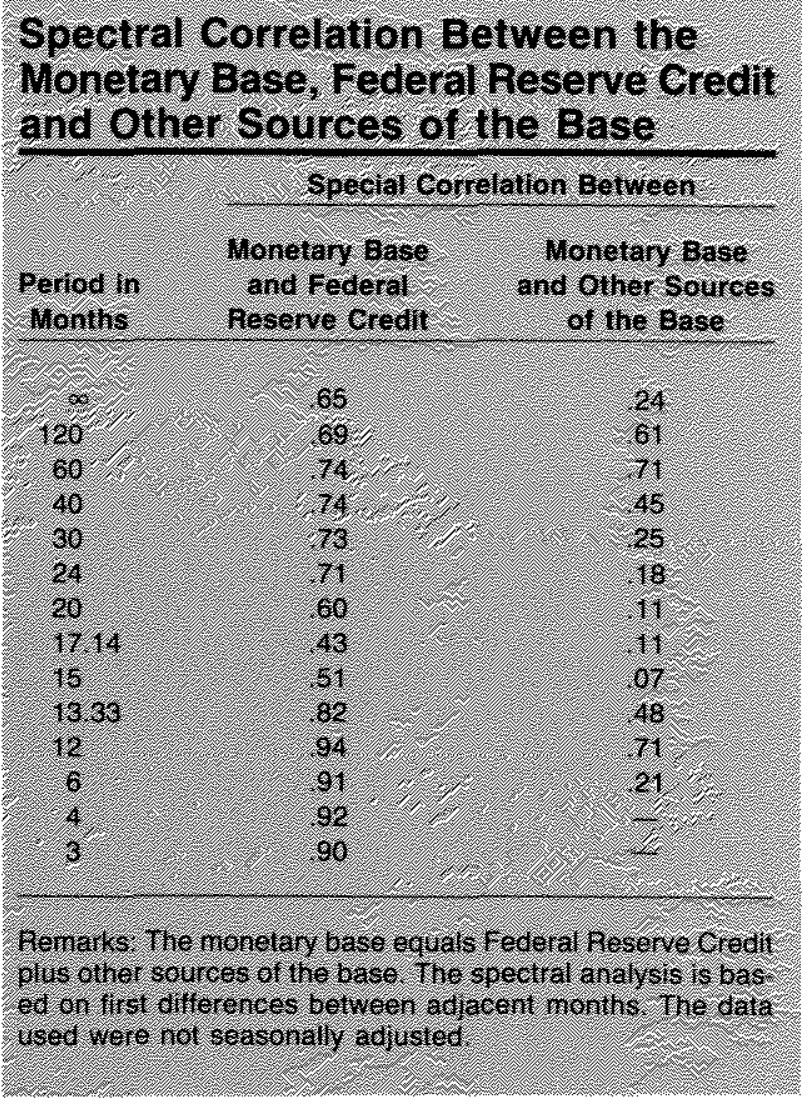

view is the Keynesian conception (not to be confused with Keynes' view), enshrined in standard formulations of the income-expenditure framework. In the view, the interest rate is the main link between money and economic activity. The other view rejects the traditional separation of economic theory into parts: national income analysis (macro economics) and price theory (micro economics). According to this other view, output and employment are explained by a suitable application of relative price theory. With regard to discussions of the impact of money and monetary actions on economic activity, this latter view has been termed the Monetarist position. This position may be divided into the weak Monetarist thesis and the strong Monetarist thesis. In a sense, both the New View and the Monetarist extension of the "traditional view" are represented in the weak Monetarist position.

The following discussions develop the weak and the strong Monetarist thesis. The weak thesis is compared with some aspects of the income-expenditure approach to the determination of national economic activity. The strong 
thesis supplements the weak thesis with special assumptions about our environment, in order to establish the role of monetary forces in the business cycle.

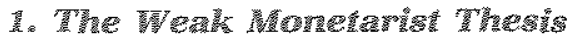

According to the weak Monetarist thesis, monetary impulses are transmitted to the economy by a relative price process which operates on money, financial assets (and liabilities), real assets, yields on assets and the production of new assets, liabilities and consumables. The general nature of this process has been described on numerous occasions and may be interpreted as evolving from ideas developed by Knut, Wicksell, Irving Fisher and John Maynard Keynes. ${ }^{17}$

The operation of relative prices between money, financial assets and real assets may be equivalently interpreted as the working of an interest rate mechanism (prices and yields of assets are inversely related). Monetary impulses are thus transmitted by the play of interest rates over a vast array of assets. Variations in interest rates change relative prices of existing assets, relative to both yields and the supply prices of new production. Acceleration or deceleration of monetary impulses are thus converted by the vartation of relative prices, or interest rates, into increased or reduced production, and subsequent revisions in the supply prices of current output.

This general conception of the transmission mechanism has important implications which conflict sharply with the Keynesian interpretation of monetary mechanisms expressed by standard income-expenditure formulations. ${ }^{18}$ In the context of standard income-expenditure analysis, fiscal actions are considered to have a "direct effect" on economic activity, whereas monetary actions are considered to have only and "indirect effect." Furthermore, a constant budget deficit has no effect on interest rates in

1The reader may consult the following studies on this aspec: Milton Friedman and David Meiselman, "The Relative Stability of Monetary Velocity and the Investment Multiplier in the United States, 1897-1958," in Stabilization Policies, prepared by the Commission on Money and Credit, Englewood Clifts, 1963. The paper listed in footnote 21 by James Tobin should also be consulted. Harry Johnson, "Monetary Theory and Policy," American Economic Review, June 1962. Karl Brunner "The Report of the Commission on Money and Credit," The Journal of Political Economy, December 1961. Karl Brunner, "Some Major Problems of Monetary Theory," Proceedings of the American Economic Association, May 1961. Karl Brunner and Allan $\mathrm{H}$. Meltzer, "The Role of Financial Institutions in a Keynesian framework, in spite of substantial accumulation of outstanding government debt when a budget deficit continually occurs. And lastly, the operation of interest rates on investment decisions has usually been rationalized with the aid of considerations based on the effects of borrowing costs.

These aspects of the income-expenditure approach may be evaluated within the framework of the weak Monetarist thesis. The effects of fiscal actions are also transmitted by the relative price mechanism. Fiscal impulses, i.e., government spending, taxing, and borrowing, operate just as "indirectly" as monetary impulses, and there is no a priori reason for believing that their speed of transmission is substantially greater than that of monetary impulses. The relative price conception of the transmission mechanism also implies that a constant budget deficit exerts a continuous influences on economic activity through persistent modifications in relative prices of financial and real assets. Lastly, the transmission of monetary impulses is not dominated by the relative importance of borrowing costs. In the process, marginal costs of liability extenston interact with marginal returns from acquisitions of financial and real assets. But interest rates on financial assets not only affect the marginal cost of liability extension, but also influence the substitution between financial and real assets. This substitution modifies prices of real assets relative to their supply prices and forms a crucial linkage of the monetary mechanisms; this linkage is usually omitted in standard income-expenditure analysis.

The description of monetary mechanisms in Davis' article approaches quite closely the notion developed by the weak Monetarist thesis. This approximation permits a useful clarification of pending issues. However, the criticisms and objections advanced by Davis do not apply to the

the Transmission Mechanism," Proceedings of the American Economic Association, May 1963. Karl Brunner

"The Relative Price Theory of Money, Output, and Employment," unpublished manuscript based on a paper presented at the Midwestern Economic Association Meetings, April 1967.

18The paper on "The Effect of Monetary Policy on Expenditures in Specific Sectors of the Economy," presented by Dr. Sherman Maisel at the meetings organized by the American Bankers Association in September 1967, exemplifies very clearly the inherited Keynesian position. The paper will be pubtished in a special issue of the Joumal of Political Economy. 
weak Monetarist position. They are addressed to another thesis, which might be usefully labeled the strong Monetarist thesis.

\section{The Strong Monetarist Thesis}

If the theoretical framework of the weak Monetarist thesis is supplemented with additional and special hypotheses, the strong Monetarist thesis is obtained. An outline of the strong thesis may be formulated in terms of three sets of forces operating simultaneously on the pace of economic activity. For convenience, they may be grouped into monetary forces, fiscal forces and other forces. The latter include technological and organizational innovation, revisions in supply prices induced by accruing information and expectation adjustments, capital accumulation, population changes and other related factors or processes.

All three sets of forces are acknowledged by the strong thesis to affect the pace of economic activity via the relative price process previously outlined. Moreover, the strong Monetarist point of view advances the crucial thesis that the variability of monetary forces (properly weighted with respect to their effect on economic activity) exceeds the variability of fiscal forces and other forces (properly weighted). It is argued further that major variabilities occurring in a subset of the other forces (e.g., expectations and revisions of supply prices induced by information arrival) are conditioned by the observed variability of monetary forces. The conjecture thus involves a comparison of monetary variability with the variability of fiscal forces and independent "other forces." According to the thesis under consideration, the variability of monetary of impulses is also large relative to the speed at which the economy absorbs the impact of environmental changes. This predominance of variability in monetary impulses implies that pronounced accelerations in monetary forces are followed subsequently by accelerations in the pace of economic activity, and that pronounced decelerations in monetary forces are followed later by retardations in economic activity.

The analysis of the monetary dynamics, using the relative price process, is accepted by both the weak and the strong Monetarist theses. This analysis implies that the regularity of the ob. served association between accelerations and decelerations of monetary forces and economic activity depends on the relative magnitude of monetary accelerations (or decelerations). The same analysis also reveals the crucial role of changes in the rate of change (second differencesl of the money stock in explanations of fluctuations in output and employment. It implies that any pronounced deceleration, occurTing at any rate of monetary growth, retards total spending. It is thus impossible to state whether any particular monetary growth, say a 10 percent annual rate, is expansionary with respect to economic activity, until one knows the previous growth rate. The monetary dynamics of the Monetarist thesis also explains the simultaneous occurrence of permanent priceinflation and fluctuations in output and employment observable in some countries.

The nature and the variability of the "Friedman lag" may also be analyzed within the framework of the Monetarist thesis. This lag measures the interval between a change in sign of the second difference in the money stock and the subsequent turning point located by the National Bureau. In general, the lag at an upper turning point will be shorter, the greater the absorption speed of the economy, and the sharper the deceleration of monetary impulses relative to the movement of fiscal forces and other forces. Vartability in the relative acceleration or deceleration of monetary forces necessarily generates the variability observed in the Friedman lag.

What evidence may be cited on behalf of the strong Monetarist thesis? Every major inflation provides support for the thesis, particularly in cases of substantial variations of monetary growth. The attempt at stabilization in the Confederacy during the Civil War forms an impressive piece of evidence in this respect. The association between monetary and economic accelerations or decelerations has also been observed by the Federal Reserve Bank of St. Louis. ${ }^{19}$ Observations from periods with diver. gent movements of monetary and fiscal forces provide further evidence. For instance, such periods occurred immediately after termination of World War II, from the end of 1947 to the fall of 1948, and again in the second half of 1966. In all three cases, monetary forces pre- 
vailed over fiscal forces. The evidence adduced here and on other occasions does not "prove" the strong Monetarist thesis, but does establish its merit for serious consideration.

Davis' examination is therefore welcomed. His objections are summarized by the following points: (a) observations of the persistent association between money and income do not permit an inference of causal direction from money to income; (b) the timing relation between money and economic activity expressed by the Friedman lag yields no evidence in support of the contention that variations in monetary growth cause fluctuations in economic activity; (c) the correlation found in cycles of moderate amplitude between magnitudes of monetary and economic changes was quite unimpressive; (d) the length of the Friedman lag does not measure the interval between emission of monetary impulse and its ultimate impact on economic activity. Furthermore, the variability of this lag is due to the simultaneous operation and interaction of monetary and non-monetary forces.

Davis' first comment (a) is of course quite true and well known in the logic of science. It is impossible to derive (logically) causal statements or any general hypotheses from observations. But we can use such observations to confirm or disconfirm such statements and hypotheses. Davis particularly emphasizes that the persistent association between money and income could be attributed to a causal influence running from economic activity to money.

Indeed it could, but our present state of knowledge rejects the notion that the observed association is essentially due to a causal influence from income on money. Evidence refuting such a notion was presented in section $C$. The existence of a mutual interaction over the shorter run between money and economic activity, however, must be fully acknowledged. Yet, this interaction results from the conception guiding policymakers which induces them to accelerate the monetary base whenever pressures on interest rates mount, and to decelerate the monetary base when these pressures wane. Admission of a mutual interaction does not dispose of the strong Monetarist thesis. This interaction, inherent in the weak thesis, is quite consistent with the strong position and has no disconfirming value. To the contrary, it offers an explanation for the occurrence of the predominant variability of monetary forces.
The same logical property applies to Davis' second argument (b). The timing relation expressed by the Friedman lag, in particular the chronological precedence of turning points in monetary growth over turning points in economic activity, can probably be explained by the influence of business conditions on the money supply. Studies in money supply theory strongly suggest this thesis and yield evidence on its behalf. The cyclical pattern of the currency ratio, and the strategy typically pursued by monetary policymakers explain this lead of monetary growth. And again, such explanation of the timing relation does not bear negatively on the strong conjecture.

The objection noted under Davis' point (c) is similarly irrelevant. His observations actually confirm the strong thesis. The latter implies that the correlation between amplitudes of monetary and income changes is itself correlated with the magnitude of monetary accelerations or decelerations. A poor correlation in cycles of moderate amplitude, therefore, yields no discriminating evidence on the validity discriminating evidence on the validity of the strong thesis. Moreover, observations describing occurrences are more appropriate relative to the formulated thesis than correlation measures. For instance, observations tending to disconfirm the strong Monetarist thesis would consist of occurrences of pronounced monetary accelerations or decelerations which are not followed by accelerated or retarded movements of economic activity.

Point (d) still remains to be considered. Once again, his observation does not bear on the strong Monetarist thesis. Davis properly cautions readers about the interpretation of the Friedman lag. The variability of this lag is probably due to the interaction of monetary and non-monetary forces, or to changes from cycle to cycle in the relative variability of monetary growth. But again, this does not affect the strong thesis. The proper interpretation of the Friedman lag, as the interval between reversals in the rate of monetary impulses and their prevalence over all other factors simultaneously operating on economic activity, usefully clarifies a concept introduced into our discussions. This clarification provides, however, no relevant evidence bearing on the questioned hypotheses.

In summary, the arguments developed by Davis do not yield any substantive evidence against the strong Monetarist thesis. Moreover, 
the discussion omits major portions of the evidence assembled in support of this position. ${ }^{20}$

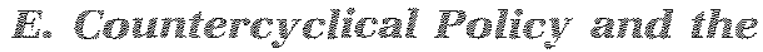

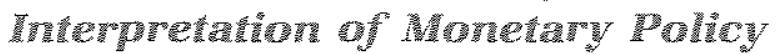

The usual assertion of the New View, attributing fluctuations of monetary growth to the public's and the banks' behavior, assumed a strategic role in the countercritique. The countercritique denied, furthermore, that monetary actions have a major impact on economic activity. With the crumbling of these two bastions, the monetary policymakers' interpretation of their own behavior becomes quite vulnerable. In a previous section, the substantial contribution of the monetary base to the fluctuations of monetary growth has been demonstrated. These facts, combined with repeated assertions that monetary policy has been largely countercyclical, suggest the existence of a pronounced discrepancy between actual behavior of the monetary authorities and their interpretation of this behavior.

A crucial question bearing on this issue pertains to the proper measure summarizing actual behavior of the monetary authorities. Two major facts should be clearly recognized. First, the monetary base consists of "money" directly issued by the authorities, and every issue of base money involves an action of the monetary authorities. This holds irrespective of their knowledge about it, or their motivation and aims. Second, variations in the base, extended by suitable adjustments to incorporate changing reserve requirement ratios, are the single most important factor influencing the behavior of the money stock. And this second point applies irrespective of whether Federal Reserve authorities are aware of it or wish it to be, or whatever their motivations of aims are. Their actual behavior, and not their motivations or

2aMilton Friedman's summary of the evidence in the FortyFourth Annual Report of the National Bureau of Economic Research is important in the respect. Davis overtooks in particular the evidence accumulated in studies of the money supply mechanism which bears on the issue raised by point (a) in the text. A persistent and uniform associa tion between money and economic activity, in spite of large changes in the structure of money supply processes, yields evidence in support of the Monetarist theses.

The reader should also consult Chapter 13 of the book by Milton Friedman and Anna Schwartz listed in footnote 9; Studies in the Quantity Theory of Money, edited by Milton Friedman, University of Chicago Press, 1956; and a doctoral dissentation by Michael W. Keran, "Monetary Policy and the Business Cycle in Postwar Japan," Ph.D. thesis at the University of Minnesota, March 1966, to be published aims, influences the monetary system and the pace of economic activity. Thus, actual changes in the monetary base are quite meaningful and appropriate measures of actual behavior of monetary authorities. ${ }^{21}$

The information presented in table IV supports the conjecture that monetary policymakers' interpretation of their own behavior has no systematic positive association with their actual behavior. Table IV was constructed on the basis of the scores assigned to changes in policies, according to the interpretation of the Federal Open Market Committee ${ }^{22}$ Positive scores were associated with each session of the FOMC which decided to make policy easier, more expansionary, less restrictive, less tight, etc., and negative scores indicate decisions to follow a tighter, less expansionary, more restrictive course. The scores varied between plus and minus one, and expressed some broad ordering of the revealed magnitude of the changes.

An examination of the sequences of scores easily shows that the period covered can be naturally partitioned into subperiods exhibiting an overwhelming occurrence of scores with a uniform sign. These subperiods are listed in the first column of table IV. The second column cumulated the scores over the subperiods listed in order to $y$ ield a very rough ranking of the policymakers' posture according to their own interpretation.

Table IV feveals that the FOMC interpreted the subperiods from August 1957 to July 1958 , and from July 1959 to December 1960 as among the most expansionary policy periods. The period from November 1949 to May 1953 appears in this account as a phase of persistently tight or restrictive policy. The next two columns list the changes of two important variables during each subperiod. The third column

as a chapter of a book edited by David Meiselman.

21The reader may also be assured by the following statement:

". . monetary policy refers particularly to determination of the supply of (the government's) demand debt ..." This demand debt coincides with the monetary base. The quote is by James Tobin, a leading architect of the New View, on p. 148 of his contribution to the Commission on Money and Credit, "An Essay on Principles of Debt Management," in Fiscal and Debt Management Policies, Prentice Hall, Englewood Cliffs, 1963.

${ }^{22}$ The scores were published as Appendix li to "An Alternative Approach to the Monetary Mechanism." See footnote 9 . 


\begin{tabular}{|c|c|c|c|}
\hline Periods & $\begin{array}{l}\text { Cumulative Scores } \\
\text { of Policymakers } \\
\text { Interpretation } \\
\text { over the Period }\end{array}$ & $\begin{array}{l}\text { Changes in free } \\
\text { Reserves over } \\
\text { the Period in } \\
9 \text { uilion }\end{array}$ & 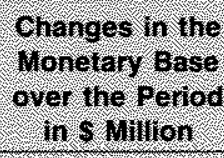 \\
\hline $11149-5153$ & -4.75 & -1030 & 45216 \\
\hline $6,53-17 / 54$ & +263 & +286 & +1321 \\
\hline 12154.10155 & -3.37 & -818 & +345 \\
\hline $11155-7156$ & +1.12 & +352 & +399 \\
\hline $8756-7157$ & -1.00 & -44 & +657 \\
\hline $8 / 57.7 / 58$ & +3.50 & +1017 & +1203 \\
\hline $7158-6659$ & -2.12 & -1059 & +531 \\
\hline $7559-12160$ & +2.62 & 1,1239 & -53 \\
\hline $1 / 61-12162$ & $=63$ & -428 & + 3288 \\
\hline
\end{tabular}

describes changes in free reserves, and the fourth column notes changes in the monetary base. A cursory examination of the columns immediately shows substantial differences in their broad association. The rank correlation between the various columns is most informative for our purposes.

These rank correlations are listed in table $\mathrm{V}$. The results expose the absence of any positive association between the policymakers' own interpretation or judgment of their stance and their actual behavior, as indicated by movements in the monetary base. The correlation coefficient between the monetary base and cumulated scores has a negative value, suggesting that a systematic divergence between stated and actual policy (as measured by the monetary base) is probable. On the other hand,

\section{Table V}

Rank Correlation Between Changes in the Monetary Base, Changes in Free Reserves and the Cumulated Scores of Policymakers' Interpretations

Gumulated scores and base

Cumulated scores and treo reserves

tree reserves and base
$+.09$

$+70$

2.26 the correlation between the policymakers' descriptions of their posture, and the movement of free reserves, is impressively close. This correlation confirms once again that the Federal Reserve authorities have traditionally used the volume of free reserves as an indicator to gauge and interpret prevailing monetary policies. Yet little evidence has been developed which establishes a causal chain leading from changes in free reserves to the pace of economic activity.

Another observation contained in table IV bears on the issue of policymakers interpretation of their own behavior. Changes in the cumulated scores and free reserves between the periods listed always move together and are perfect in terms of direction. By comparison, the co-movement between cumulated scores and changes in the monetary base is quite haphazard; only three out of eight changes between periods move together. This degree of co-movement between cumulated scores and the monetary base could have occurred by pure chance with a probability greater than .2 , whereas the probability of the perfect comovement between cumulated scores and free reserves occurring as a matter of pure chance is less than .004 . The traditional selection of free reserves or money market conditions as an indicator to interpret prevailing monetary policy and to gauge the relative thrust applied by policy, forms the major reason for the negative association (or at least random association) between stated and actual policy. 
Attempts at rebuttal to the above analysis often emphasize that policymakers are neither interested in the monetary base, nor do they attach any significance to it. This argument is advanced to support the claim that the behavior of the monetary base is irrelevant for a proper examination of policymakers' intended behavior. This argument disregards, however, the facts stated earlier, namely, movements in the monetary base are under the direct control and are the sole responsibility of the monetary authorities. It also disregards the fact that actions may yield consequences which are independent of motivations shaping the actions.

These considerations are sufficient to acknowledge the relevance of the monetary base as a measure summarizing the actual behaviof of monetary authorities. However, they alone are not sufficient to determine whether the base is the most reliable indicator of monetary policy. Other magnitudes such as interest rates, bank credit and free reserves have been advanced with plausible arguments to serve as indicators. A rational procedure must be designed to determine which of the possible entities frequently used for scaling policy yields the most reliable results.

This indicator problem is still very poorly understood, mainly because of ambiguous use of economic language in most discussions of monetary policy. The term "indicator" occurs with a variety of meanings in discussions, and so do the terms "target" and "guide." The indicator problem, understood in its technical sense, is the determination of an optimal scale justifying interpretations of the authorities' actual behavior by means of comparative state. ments. A typical statement is that policy $X$ is more expansionary than policy $Y$, or that current policy has become more (or less) expansionary. Whenever we use a comparative concept, we implicitly rely on an ordering scale.

The indicator problem has not been given adequate treatment in the literature, and the recognition of its logical structure is often obstructed by inadequate analysis. It is, for instance, not sufficient to emphasize the proposition that the money supply can be a "misleading guide to the proper interpretation of monetary policy." This proposition can be easily demon. strated for a wide variety of models and hypotheses. However, it establishes very little. The same theories usually demonstrate that the rate of interest, free reserves, or bank credit can also be very misleading guides to monetary policy. Thus, we can obtain a series of propositions about a vast array of entities, asserting that each one can be a very misleading guide to the interpretation of policy. We only reach a useless stalemate in this situation.

The usual solution to the indicator problem at the present time is a decision based on mystical insight supplemented by some impressionistic arguments. The most frequently advanced arguments emphasize that central banks operate directly on credit markets where interest rates are formed, or that the interest mechanism forms the centerpiece of the transmission pro. cess. Accordingly, in both cases market interest rates should "obviously" emerge as the relevant indicator of monetary policy.

These arguments on behalf of market interest rates are mostly supplied by economists. The monetary authorities' choice of money market conditions as an indicator evolved from a different background. But in recent years a subtle change has occurred. One frequently encounters arguments which essentially deny either the existence of the indicator problem or its rational solution. A favorite line asserts that "the world is very complex" and consequently it is impossible or inadmissible to use a single scale to interpret policy. According to this view, one has to consider and weigh many things in order to obtain a "realistic" assessment in a complicated world.

This position has little merit. The objection to a "single scale" misconstrues the very nature of the problem. Once we decide to discuss monetary policy in term of comparative statements, an ordinal scale is required in order to provide a logical basis for such statements. A multiplicity of scales effectively eliminates the use of comparative statements. Of course, a single scale may be a function of multiple arguments, but such multiplicity of arguments should not be confused with a multiplicity of scales. Policymakers and economists should therefore realize that one either provides a rational procedure which justifies interpretations of monetary policy by means of comparative statements, or that one abandons any pretense of meaningful or intellectually honest discussion of such policy.

Solution of the indicator problem in the technical sense appears obstructed on occasion by a prevalent confusion with an entirely different problem confronting the central banker- 
the target problem. This problem results from the prevailing uncertainty concerning the nature of the transmission mechanism and the substantial lags in the dynamics of monetary processes.

In the context of perfect information, the indicator problem becomes trivial and the target problem vanishes. But perfect information is the privilege of economists' discourse on policy; central bankers cannot afford this luxury. The im pact of their actions are both delayed and uncertain. Moreover, the ultimate goals of monetary policy (targets in the Tinbergen-Theil sense) appear remote to the manager executing general policy directives. Policymakers will be inclined under these circumstances to insert a more immediate target between their ultimate goals and their actions. These targets should be reliably observable with a minimal lag.

It is quite understandable that central bankers traditionally use various measures of money market conditions, with somewhat shifting weights, as a target guiding the continuous adjustment of their policy variables. This response to the uncertainties and lags in the dynamics of the monetary mechanism is very rational indeed. However, once we recognize the rationality of such behavior, we should also consider the rationality of using a particular target. The choice of a target still remains a problem, and the very nature of this problem is inadequately understood at this state.

This is not the place to examine the indicator and target problem in detail. A possible solution to both problems has been developed on another occasion. ${ }^{23}$ The solutions apply decision theoretic procedures and concepts from control vheory to the determination of an optimal choice of both indicator and target. Both problems are in principle solvable, in spite of the "complexity of the world." Consequently, there is little excuse for failing to develop rational monetary policy procedures.

\section{CONGWUSION}

A program for applying economic analysis to financial markets and financial institutions is certainly acceptable and worth pursuing. This program suggests that the public and banks in- teract in the determination of bank credit, interest rates, and the money stock, in response to the behavior of monetary authorities. But the recognition of such interaction implies nothing with respect to the relative importance of the causal forces generating cyclical fluctuations of monetary growth. Neither does it bear on the quality of alternative empirical hypotheses, or the relative usefulness of various magnitudes or conditions which might be proposed as an indicator to judge the actual thrust applied by monetary policy to the pace of economic activity.

The Monetarist thesis has been put forth in the form of well structured hypotheses which are supported by empirical evidence. This extensive research in the area of monetary policy has established that: (i) Federal Reserve actions dominate the movement of the monetary base over time; (ii) movements of the monetary base dominate movements of the money supply over the business cycle; and, (iii) accelerations or decelerations of the money supply are closely followed by accelerations or decelerations in economic activity. Therefore, the Monetarist thesis puts forth the proposition that actions of the Federal Reserve are transmitted to economic activity via the resulting movements in the monetary base and money supply, which initiate the adjustments in relative prices of assets, liabilities, and the production of new assets.

The New View, as put forth by the countercritique, has offered thus far neither analysis nor evidence pertaining relevantly to an explanation of variations in monetary growth. Moreover, the countercritique has not developed, on acceptable logical grounds, a systematic justification for the abundant supply of statements characterizing policy in terms of its effects on the economy. Nor has it developed a systematic justification for the choice of money market conditions as an optimal target guiding the execution of open market operations.

But rational policy procedures require both a reliable interpretation and an adequate determination of the course of policy. The necessary conditions for rational policy are certainly not satisfied if policies actually retarding economic activity are viewed to be expansionary, as in the
29The reader may consult the chapter by Karl Brunner and Allan H. Meltzer on "Targets and indicators of Monetary Policy," in the book of the same title, edited by Kart Brun- ner. The book will be published by Chandler House Publishing Co., Belmont, California. 
case of the 1960-61 recession, or, if inflationary actions are viewed as being restrictive, as in the first half of 1966.

The major questions addressed to our monetary policymakers, their advisors and consul. tants remain: How do you justify your inter- pretation of policy, and how do you actually ex plain the fluctuations of monetary growth? The major contentions of the academic critics of the past performance of monetary authorities could possibly be quite false, but this should be demonstrated by appropriate analysis and relevant evidence. 